\title{
Patient Literacy
}

\section{A Barrier to Quality of Care}

$\mathbf{W}$ e assume that health care is accessible once the patient walks through the examining room door. Yet access to care requires more than the patient's presence; it also requires that the patient engage in the process of care. Low literacy, though not so obvious a barrier as cost or transportation, limits access by preventing patients from engaging fully in the process of care. ${ }^{1}$ In this issue, Baker and colleagues describe how important outcomes of care such as health status and hospitalization are linked to literacy. ${ }^{2}$ Even after adjusting for confounding sociodemographic variables, they found that patients with low literacy skills had poorer health, higher rates of hospitalization, and incurred higher health care costs than patients with adequate literacy.

To measure literacy in this context, Baker et al. used the Test of Functional Health Literacy Assessment (TOFHLA), which was developed by Parker and colleagues and is based on a patient's ability to perform health-related tasks that require reading and computational skills. These tasks include taking medication, keeping appointments, preparing for tests and procedures, and giving informed consent. ${ }^{3}$ Using TOFHLA, Baker and colleagues demonstrated that fully one third of patients admitted to their inner-city hospital were functionally illiterate, and another $13 \%$ were only marginally literate. ${ }^{2}$ These findings are consistent with previous research reporting inadequate or marginal functional health literacy in 35\% of English-speaking patients and $62 \%$ of Spanish-speaking patients seeking care at public, inner-city hospitals. Among patients more than 60 years of age, low literacy was present in $80 \%$ for both Englishspeaking and Spanish-speaking patients. ${ }^{4}$

With low literacy skills so prevalent among the general population, physicians are likely to encounter patients with this limitation. Nevertheless, physicians are unlikely to recognize patients with poor literacy skills because of common misconceptions. ${ }^{5}$ In their comprehensive overview of teaching patients with low literacy skills, Doak and colleagues $^{6}$ describe several such widely held misconceptions: people with low literacy skills are intellectually impaired and slow learners; most adults with low literacy skills are poor, immigrants, and minorities; years of schooling predict literacy levels; and people will tell you if they cannot read or they will get help when they need it. ${ }^{6}$

In fact, most people with low literacy skills are of average intelligence and function reasonably well by compensating for their lack of reading skills. ${ }^{6,7}$ The circumstances underlying low literacy are varied. Limited education accounts for much of poor literacy in the elderly and in new immigrants. Learning disabilities may account for a large proportion of the poor literacy skills in younger people who have formal education. ${ }^{8}$ Although low literacy occurs more frequently among persons of lower socioeconomic status, the poorly educated, the elderly, immigrants, the disabled, and American-born ethnic minorities, it is not limited to these groups. In absolute terms the majority of those in the low-literate population are white, native-born Americans. ${ }^{8}$ Furthermore, more than $20 \%$ of adults tested in the National Adult Literacy Survey and $18 \%$ of patients in the Baker study who had the lowest levels of literacy had a high school diploma. Years of schooling, as noted by Baker, reflect the amount of education, not the number or the type of skills acquired. Indeed, adults typically read three to five levels lower than the grade level of education they completed.7,9

Commonly held expectations for reading ability and social approbation for illiteracy inhibit disclosure, silence patients, and discourage patients' efforts to seek information and request assistance. Parikh and colleagues reported that one third of the patients with low functional health literacy on the TOFHLA that they studied did not acknowledge difficulty reading or understanding what they read. ${ }^{10}$ Among patients who did admit trouble reading, $40 \%$ felt shame and more than 50\% had never told their spouses or children about their reading problem.

A search of the literature on health literacy published between 1990 and 1998 yielded more than 175 publications. ${ }^{11}$ The majority of these focused on the gap between the literacy required to read health education materials and the average patient's reading ability. Many proposed solutions use language simplification and audiovisual materials, ${ }^{12-19}$ while some propose nontraditional approaches using learner-centered and participatory methods of materials development. ${ }^{20-21}$ With few exceptions, this literature falls short, however, in explaining how literacy influences health behavior and outcomes.

Poor literacy may be a marker for an array of problems that go far beyond reading ability. Communication difficulties faced by patients may, in part, be due to differences in vocabulary, but also to differences in the structure and complexity of speech used by literate and lowliterate populations. LeVine and colleagues provided some insight into the mechanisms in several studies conducted in developing countries. ${ }^{22}$ These investigators found a relation between literacy level and speech comprehension. They suggested that literacy builds a cognitive process that facilitates the comprehension of spoken language, including health messages. Even further, Dexter and colleagues demonstrated that poor literacy skill was linked with inadequate health-related descriptions. ${ }^{23}$ Therefore, low literacy not only interferes with patient education, but also may complicate history taking.

Low-literate patients in the United States described serious and widespread communication difficulties with their health providers in focus groups and individual interviews. ${ }^{24}$ Patients said providers did not listen and did not provide information about the patients' problems and treat- 
ments in ways they could understand. Despite this problem, few patients asked questions or told their providers about the difficulties, and few disclosed their poor literacy to providers. Though some patients concealed this information out of embarrassment, others simply did not think it was something the physician would be interested in knowing.

Other than advice for better-designed, learner-centered materials, there is little in the literature to help physicians communicate better with their low-literate patients. Consequently, it is not surprising that few physicians feel competent to respond when they recognize patients with poor literacy skills. ${ }^{1,5}$

There is some general guidance for increasing patient recall and understanding. ${ }^{25-27}$ These approaches advise organizing information into logical blocks, simplifying the message, making the message specific rather than general, repeating the message, summarizing, checking understanding by asking patients to give an explanation in their own words, and reinforcing the most important messages. Even patients with good literacy skills should benefit from these techniques.

Beyond these specific strategies, there is considerable evidence that patient-centered interviewing skills can help transcend the social, cultural, educational, and emotional barriers between patients and their physicians. ${ }^{28}$ Descriptions that place medical concerns in a personal context, for example, by explaining the effect of treatment on the patient's daily activities, social relationships, and feelings, better help patients understand than technical and biomedical descriptions. As noted by sociologist Eliot Mishler, these types of exchanges translate the largely incomprehensible biomedical monologues of many medical visits into a dialogue reflecting the lived experience of the patient's world. ${ }^{29}$

The patient who walks through the examination room door may have gained access to a medical facility, but access to effective health care will remain elusive if communication barriers have not been fully addressed.-DEBRA L. ROTER, DRPH, Department of Health Policy and Management, Johns Hopkins School of Public Health, Baltimore, Md., Rima E. RudD, ScD, Department of Health and Social Behavior, Harvard School of Public Health, Boston, Mass., and JoHn Comings, EDD, National Center for the Study of Adult Learning and Literacy, Harvard University Graduate School of Education, Cambridge, Mass.

\section{REFERENCES}

1. Miles S, Davis T. Patients who can't read: implications for the health care system. JAMA. 1995;274:1719-20.

2. Baker DW, Parker RM, Clark WS. Health literacy and the risk of hospital admission. J Gen Intern Med. 1998;13:791-8.

3. Parker RM, Baker DW, Williams MV, Nurss JR. The test of functional health literacy in adults: a new instrument for measuring patients' literacy skills. J Gen Intern Med. 1995;10:537-41.

4. Williams MV, Parker RM, Baker DW, et al. Inadequate functional health literacy among patients at two public hospitals. JAMA. 1995; 274:1677-82.
5. Weiss BD, Coyne C. Communicating with patients who cannot read. N Engl J Med. 1997;4:272-3.

6. Doak CC, Doak LG, Root JH. Teaching Patients with Low Literacy Skills. 2nd ed. Philadelphia, Pa: JB Lippincott Company; 1996.

7. Jackson RH, Davis TC, Bairnsfather LE, George RB, Crouch MA, Gault $H$. Patient reading ability: an overlooked problem in health care. South Med J. 1991;84:1172-5.

8. Kirsch IS, Jungeblut A, Jenkins L, Kolstad A. Adult Literacy in America: A First Look at the Results of the National Adult Literacy Survey. Washington, DC: Department of Education; 1993.

9. Doak LG, Doak CC. Patient comprehension profiles. Recent findings and strategies. Patient Counsel Health Educ. 1980;2:101-6.

10. Parikh NS, Parker RM, Nurss JR, Baker DW, Williams MV. Shame and health literacy: the unspoken connection. Patient Educ Counsel. 1996;27:33-9.

11. Rudd RE, Colton T. An Overview of Medical and Public Health Literature Addressing Literacy Issues: An Annotated Bibliography. NCSALL Reports 7. Boston, Mass: World Education; 1998.

12. Richwald G, Wamsley M, Coulson A, Morisky D. Are condom instructions readable? Results of a readability study. Public Health Rep. 1988;103:355-9.

13. Powers RD. Emergency department patient literacy and the readability of patient-directed materials. Ann Emerg Med. 1988;17: 124-6.

14. Meade C, Byrd J. Patient literacy and the readability of smoking education literature. Am J Public Health. 1989;79:204-6.

15. Beaver K, Luker K. Readability of patient information booklets for women with breast cancer. Patient Educ Counsel. 1997;31:95-102.

16. Spandorfer JM, Karras DJ, Hughes LA, Caputo C. Comprehension of discharge instructions by patients in an urban emergency department. Ann Emerg Med. 1995;25:71-4.

17. Meade CD, McKinney P, Barnas GP. Educating patients with limited literacy skills: the effectiveness of printed and videotaped materials about colon cancer. Am J Public Health. 1994;84:119-21.

18. TenHave TR, Van Horn B, Kumanyika S, Askov E, Matthews Y, Adams-Campbell LL. Literacy assessment in cardiovascular nutrition education setting. Patient Educ Counsel. 1997;31:139-50.

19. Davis TC, Fredrickson DD, Arnold C, Murphy PW, Herbst M, Bocchini JA. A polio immunization pamphlet with increased appeal and simplified language does not improve comprehension to an acceptable level. Patient Educ Counsel. 1998;33:25-37.

20. Roter DL, Rudd R, Keogh J, Robinson B. Worker produced health education materials for the construction trades. Int $\mathrm{Q}$ Commun Health Educ. 1987;7:109-21.

21. Rudd RE, Comings J. Learner developed materials: an empowering product. Health Educ Q. 1994;21:313-28.

22. LeVine R, Dexter E, Velasco P, et al. Maternal literacy and health care in three countries: a preliminary report. Health Transition Rev. 1994;4:186-91.

23. Dexter ER, LeVine SE, Velasco PM. Maternal schooling and healthrelated language and literacy skills in rural Mexico. Comp Educ Rev. 1998;42:139-62.

24. Baker DW, Parker RM, Williams MV, et al. The health care experience of patients with low literacy. Arch Fam Med. 1996;5:329-34.

25. Ley P. Patients' understanding and recall in clinical communication failure. In: Pendleton D, Hasler J, eds. Doctor-Patient Communication. London, England: Academic Press Inc; 1983:89-107.

26. Roter D. Physician/patient communication: transmission of information and patient effects. Maryland State Med J. 1983;32:250-71.

27. Stewart M. Patient recall and comprehension after the medical visit. In: Lipkin M, Putnam S, Lazare A, eds. The Medical Interview: Clinical Care, Education, and Research. New York, NY: Springer-Verlag; 1995:525-9.

28. Stewart M, Brown BJ, Weston WW, McWhinney I, McWilliam CL, Freeman TR. Patient-Centered Medicine: Transforming the Clinical Method. Thousand Oaks, Calif: Sage Publications; 1995.

29. Mishler EG. The Discourse of Medicine: Dialectics of Medical Interviews. Norwood, NJ: Ablex; 1984. 